\title{
STRATEGI PENGEMBANGAN WISATA D'MOOAT DI DESA MOAT KECAMATAN MOAT KABUPATEN BOLAANG MONGONDOW TIMUR
}

\author{
Amelia Priska Hontong \\ Tommy Fredy Lolowang \\ Agnes Estephina Loho
}

\begin{tabular}{lll}
\hline Naskah diterima melalui Email Jurnal Ilmiah agrisosioekonomi@ unsrat.ac.id & $:$ & Rabu, 29 Januari 2020 \\
Disetujui diterbitkan & $:$ & Jumat, 29 Mei 2020 \\
\hline
\end{tabular}

\begin{abstract}
The purpose of this study was to determine the D'MOOAT Tourism development strategy in Moat Village, Moat District, Bolaang Mongondow Regency. This research lasted for 3 months, from February to April 2019. The data used in this study were primary data and secondary data. Primary data were obtained from direct interviews with 51 people consisting of D'MOOAT owners, employees, Sangadi (Head of Village) and visitors who came to the tourist attractions. This study uses a SWOT analysis model (Strengths, Weaknesses, Opportunity, Threats). The results showed that the D'MOOAT tourist attraction has a very attractive tourist attraction that offers a natural panorama of the Moat lake where the playground for children also offers a view of the strawberry garden and ornamental flowers which are an attraction for tourists who come to these attractions. ${ }^{* e p r m}{ }^{*}$
\end{abstract}

Keywords: D'MOOAT Tourism, Development Strategy, SWOT

\begin{abstract}
ABSTRAK
Tujuan penelitian ini adalah untuk mengetahui strategi pengembanganWisata D’MOOAT di Desa Moat Kecamatan Moat Kabupaten Bolaang Mongondow Timur. Penelitian ini berlangsung selama 3 bulan yaitu bulan Februari sampai April 2019. Data yang digunakan dalam penelitian ini yaitu data primer dan data sekunder. Data primer diperoleh dari wawancara langsung pada 51 orang yang terdiri atas pemilik D’MOOAT, karyawan, Sangadi (Kepala Desa) dan pengunjung yang datang ke tempat wisata. Penelitian ini mengunakan model analisis SWOT (Strenghs, Weaknesses, Opportunity, Threats ). Hasil penelitian menunjukkan bahwa tempat wisata D'MOOAT memiliki tempat wisata yang sangat menarik yang menawarkan panorama alam danau Moat tempat bermain bagi anak juga menawarkan pemandangan kebun stroberi dan bunga hias yang menjadi daya tarik bagi wisatawan yang datang ke tempat wisata ini. ${ }^{* e p r m *}$
\end{abstract}

Kata kunci : Wisata D’MOOAT, Strategi Pengembangan, SWOT

Agrisosioekonomi: 


\section{PENDAHULUAN}

\section{Latar Belakang}

Pengembangan kepariwisataan pada umumnya diarahkan sebagai sektor andalan untuk mendorong pertumbuhan ekonomi, peningkatan pendapatan daerah, memberdayakan perekonomian masyarakat, memperluas lapangan kerja dan kesempatan berusaha, serta meningkatkan pengenalan dan pemasaran produk dalam rangka meningkatkan kesejahteraan masyarakat.

Sulawesi Utara merupakan daerah yang memiliki potensi di bidang pariwisata sehingga menjadi satu sumber perekonomian. Potensi wisata di Sulawesi Utara cukup beragam diantaranya wisata alam, wisata bahari, dan wisata budaya. Moat adalah daerah dataran tinggi $1100 \mathrm{M}$ diatas permukaan laut, memiliki hawa yang sejuk dan sehat, selain itu Desa Moat memiliki pemandangan alam yang indah dan potensi berkembang tempat wisata mulai dari villa indah Moat, Cafe Love, Wisata Wisma, kacamata Indah dan Cafe Molengku. Saat ini Desa Moat terkenal dengan tempat- tempat wisata yang ada selain pemandangan, Desa Moat juga memiliki potensi yang sangat besar dan mendukung objek-objek wisata yaitu wisata alam, agrowisata, kuliner dan lain-lain.

Salah satu tempat wisata yang menawarkan semua potensi tersebut adalah D'MOOAT, tempat wisata D'MOOAT menawarkan wisata alam yaitu pemandangan dan keindahan, agrowisata seperti kebun stroberi, kebun bunga, wisata kuliner di mana tersedia cafe di dalam tempat wisata, wahana bermain bagi anak-anak dan tempat swafoto yang unik dan menarik, sedangkan untuk potensi alam yang ada masih dalam tahap pengembangan selanjutnya.

\section{Konsep Strategi}

Menurut Abdurahman (2015) mengatakan bahwa strategi adalah suatu kesatuan rencana yang menyeluruh, komprehensif dan terpadu yang diarakan untuk mencapai tujuan perusahaan. strategi berperan penting pada era global dan perdagangan bebas sekarang ini ketika persaingan semakin hebat.

Strategi adalah suatu proses berkesinambungan yang membuat organisasi secara keseluruhan dapat cocok dengan lingkungannya, atau dengan kata lain, organisasi secara keseluruhan dapat selalu responsif terhadap perubahan-perubahan di dalam lingkungan baik yang bersifat internal maupun eksternal (Dirgantoro, 2001).

\section{Perumusan strategi}

Perumusan strategi harus disesuaikan dengan implementasi. Tujuan dari analisis strategi adalah membantu hal-hal yang dihadapi terkait dengan peluang dan ancaman eksternal serta peluang dan keterbatasan internal. Esesensi perumusan strategi adalah evaluasi pelaksanaan kegiatan dan usaha untuk menjadikan lebih efektif. Hal ini dilakukan karena strategi dapat menjadi usang sesuia perkembangan.

Teknik perumusan strategi yang penting diintegrasikan dalam tiga tahapan yaitu:

a. Tahap input: untuk meringkas informasi dasar yang dibutuhkan dalam merumuskan strategi ndengan menggunakan matriks evaluasi faktor internal (EFI), Evaluasi Faktor Eksternal (EFE), dan matriks profil persaingan (Competitive Profil Matrix).

b. Tahap pencocokan: berfokus pada penciptaan alternatif strategis yang layak dengan mencocokan faktor eksternal dan internal kunci. Tahap ini mencakup penggunaan matriks kekuatan-kelemahan-peluangancaman.

c. Tahap keputusan: melibatkan strategi tunggal yaitu matriks perencanaan strategi kuantitatif (Quantitatif Stategic Planning).

\section{Konsep Pariwisata}

Pariwisata merupakan rangkaian kegiatan yang dilakukan oleh manusia baik secara perorangan maupun kelompok di dalam wilayah negara lain. Kegiatan tersebut menggunakan kemudahan, jasa dan faktor penunjang lainnya yang diadakan oleh pemerintah dan atau masyarakat, agar dapat mewujudkan keinginan wisatawan (Karyono, 1997 dalam Widyastuti 2013).

Pengertian Pariwisata adalah segala sesuatu yang berhubungan dengan wisata, termasuk pengusahaan objek dan daya tarik wisata serta usahausaha yang berhubungan dengan penyelenggaraan pariwisata, dengan demikian pariwisata meliputi:

1. Semua kegiatan yang berhubungan dengan perjalanan wisata.

2. Pengusahaan objek dan daya tarik wisata seperti: kawasan wisata, Taman rekreasi, kawasan peninggalan sejarah, museum, pagelaran seni budaya, tata kehidupan masyarakat atau yang bersifat alamiah: keindahan alam, gunung berapi, danau, pantai. 
3. Pengusahaan jasa dan sarana pariwisata yaitu: usaha jasa pariwisata (biro perjalanan wisata, agen perjalanan wisata, konvensi, perjalanan insentif dan pameran, konsultan pariwisata, informasi pariwisata). Usaha sarana pariwisata yang terdiri dari akomodasi, rumah makan, bar, angkutan wisata.

\section{Pariwisata menurut para ahli}

Menurut Suwantoro (2004), pariwisata adalah suatu proses kepergian sementara dari seseorang atau lebih menuju tempat lain di luar tempat tinggalnya. Dorongan kepergian adalah karena berbagai kepentingan, baik karena kepergian ekonomi, sosial, kebudayaan, politik, agama, kesehatan maupun kepentingan lain seperti karena sekedar ingin tahu, menambah pengalaman ataupun belajar.

\section{Analisis SWOT \\ Definisi analisis SWOT}

Analisis SWOT merupakan instrumen analisis yang ampuh bila digunakan dengan tepat. SWOT merupakan akronim untuk kata-kata Strenghts (kekuatan), Weaknesses (kelemahan), Opportunities (peluang), Threats (ancaman). Faktor kekuatan dan kelemahan terdapat dalam organisasi, sedangkan peluang dan ancaman merupakan faktor lingkungan yang dihadapi oleh perusahaan. Keampuhan analisis SWOT terletak pada kemampuan para penentu strategi perusahaan untuk memaksimalkan faktor kekuatan dan pemanfaatan peluang sehingga sekaligus meminimalisasi kelemahan dan menekan dampak ancaman. Jika para penentu strategi perusahaan mampu melakukan kedua hal tersebut, maka menentukan dan memilih straregi yang efektif akan membuahkan hasil (Siagian, 2017).

\section{Matriks IFAS dan Matriks EFAS}

Faktor- faktor strategis internal dan eksternal di berikan bobot dan nilai (ranting) berdasarkan pertimbangan propesonal. Pertimbangan propesional adalah pertimbangan berdasarkan keahliannya, kompeten dengan sesuatu yang dipertimbangkannya.

Data yang telah diperoleh dari hasil wawancara sekaligus dengan kuesioner yang telah diolah menghasilkan bobot dan ranting, kemudian nilai-nilai tesebut di masukkan kedalam matriks IFAS dan EFAS. Matriks IFAS dan EFAS dapat dilihat pada tabel 1 sebagai berikut.

\begin{tabular}{|c|c|c|c|}
\hline $\begin{array}{c}\text { Faktor } \\
\text { Strategi }\end{array}$ & Bobot & Rating & Skor \\
\hline \multicolumn{4}{|l|}{ INTERNAL } \\
\hline Kekuatan & $\mathrm{S} 1(0,0-1,0)$ & S2 (1-4) & $\begin{array}{l}\mathrm{S} 1 \times \mathrm{S} 2=\mathrm{S} 3 \\
\mathrm{~W} 1 \times \mathrm{W} 2=\end{array}$ \\
\hline Kelemahan & W1 $(0,0-1,0)$ & W2 (1-4) & W3 \\
\hline Total & 1,0 & & \\
\hline Faktor Strategi & Bobot & Rating & Skor \\
\hline \multicolumn{4}{|l|}{ EKSTERNAL } \\
\hline Peluang & O1 $(0,0-1,0)$ & O2 (1-4) & $\mathrm{O} 1 \times \mathrm{O} 2=\mathrm{O} 3$ \\
\hline Ancaman & $\mathrm{T} 1(0,0-1,0)$ & $\mathrm{T} 2(1-4)$ & $\mathrm{T} 1 \times \mathrm{T} 2=\mathrm{T} 3$ \\
\hline Total & 1,0 & & \\
\hline
\end{tabular}

Langkah - langkah membuat Matriks IFAS dan EFAS yaitu sebagai berikut

a) Masukan faktor - faktor yang menjadi kekuatan, kelemahan, peluang, dan ancaman pada kolom 1

b) Berikan bobot masing-masing faktor strategis pada kolom 2, dengan skala 1,0 (sangat penting) sampai dengan 0,0 (tidak penting). Samua bobot tersebut jumlah tidak melebihi dari skor total $=1,0$.

c) Berikan bobot masing -masing faktor strategis pada kolom 3, dengan skala mulai dari 4 (outstanding) sampai dengan 1 (Poor), terhadap kondisi usaha yang bersangkutan. Pemberian nilai ranting untuk faktor kekuatan dan peluang bersifat positif (kekuatan dan peluang yang semakin besar diberi ranting +4 ), tetapi jika kekuatan dan peluangnya kecil, diberi ranting +1 . Pemberian nilai ranting kelemahan dan ancaman adalah kebalikannya. Misalnya, jika nilai kelemahan dan ancaman sangat besar, rantingnya adalah satu, sebaliknya, jika nilai kelemahan dan ancamannya kecil di beri ranting 4 .

d) Kalikan bobot dengan nilai (ranting) untuk memperoleh faktor pembobotan dalam kolom 4. Hasilnya berupa skor pembobotan untuk masing-masing faktor yang nilai bervariasi mulai dari 4,0 (outstanding) sampai dengan 1,0 (poor).

e) Jumlahkan skor pembobotan (pada kolom 4), untuk memperoleh total skor pembobotan bagi usaha yang bersangkutan. Nilai total ini menunjukan bagaimana usaha ini bereaksi terhadap faktor-faktor strategis internalnya. Skor total ini sangat digunakan untuk membandingkan usaha ini dengan usaha lainnya dalam kelompok usaha yang sama. 


\section{Diagram Analisis SWOT}

Mengambarkan kondisi dalam perusahaan menghadapi dan memanfaatkan kekuatan, kelemahan, peluang dan ancaman.

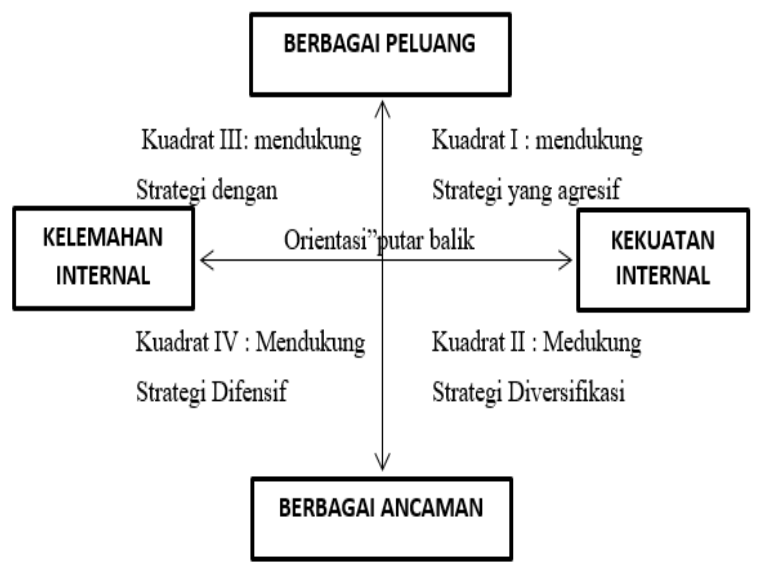

Gambar 2. Diagram Analisis SWOT

Kaudrat I: Ini merupakan situasi yang sangat menguntungkan. Perusahaan tersebut memiliki peluang dan kekuatan sehingga dapat memanfaatkan peluang yang ada. Strategi yang harus diterapkan dalam kondisi ini adalah mendukung kebijakan pertumbuhan yang agresif (growthoriented strategy).

Kuadrat II: Meskipun menghadapi berbagai ancaman, perusahaan ini masih memiliki kekuatan dari segi internal. Strategi yang harus diterapkan adalah menggunakan kekuatan untuk memanfaatkan peluang jangka panjang dengan cara strategi diversifikasi (Produk Pasar).

Kuadrat III: Perusahaan menghadapi peluang pasar yang sangat besar, tetapi dilain pihak, ia menghadapi beberapa kendala/kelemahan internal. Fokus stategi perusahaan adalah meminimalkan masalah-masalah internal perusahaan sehingga dapat merebut peluang pasar yang lebih baik.

Kuadrat IV: Ini merupakan situasi sangat tidak menguntungkan, perusahaan tersebut menghadapi berbagai ancaman dan kelemahan internal.

\section{Matriks SWOT (Strength Weaknesess, Opportunities, Thyreats)}

Analisis SWOT adalah intensifikasi bebrbagai faktor secara sitematis untuk merumuskan strategi. Matriks SWOT analisis ini didasarkan pada logika yang dapat memaksimalkan kekuatan (Strength) dan peluang (opportunities) namun secara bersama-sama meminimalkan kelemahan (weaknesess) dan ancaman (Threats). Analisis ini umumnya dilakukan untuk membahas kondisi alternatif dasar yang dapat dijadikan pertimbangan.

\begin{tabular}{|c|c|c|}
\hline EFAS & $\begin{array}{l}\text { Kekuatan } \\
\text { (Strength) } \\
\text { tentukan faktor- } \\
\text { faktor kekuatan } \\
\text { internal }\end{array}$ & $\begin{array}{l}\text { Kelemahan } \\
\text { (Weaknesess) } \\
\text { tentukan faktor- } \\
\text { faktor kelemahan } \\
\text { internal }\end{array}$ \\
\hline $\begin{array}{l}\text { Peluang } \\
\text { (Opportunities) } \\
\text { Tentukan Faktor } \\
\text { peluang Eksternal }\end{array}$ & $\begin{array}{l}\text { Strategi S-O } \\
\text { Ciptakan Strategi } \\
\text { mengunakan } \\
\text { kekuatan untuk } \\
\text { memanfaatkan } \\
\text { peluang }\end{array}$ & $\begin{array}{l}\text { Strategi W-O } \\
\text { Ciptakan strategi } \\
\text { meminimalkan } \\
\text { kelemahan untuk } \\
\text { memanfaatkan } \\
\text { peluang }\end{array}$ \\
\hline $\begin{array}{lr}\text { Ancaman } & \\
\text { (Threats, } & \text { T) } \\
\text { Tentukan faktor } \\
\text { ancaman } \\
\text { eksternal }\end{array}$ & $\begin{array}{lr}\text { Strategi } & \text { S-T } \\
\text { Ciptakan strategi } \\
\text { menggunakan } \\
\text { kekuatan untuk } \\
\text { mengatasi } \\
\text { ancaman }\end{array}$ & $\begin{array}{l}\text { Strategi } \text { W-T } \\
\text { Ciptakan strategi } \\
\text { meminimalkan } \\
\text { kelemahan untuk } \\
\text { menhindari } \\
\text { ancaman }\end{array}$ \\
\hline
\end{tabular}

\section{Rumusan Masalah}

Berdasarkan latar belakang tersebut, maka perumusan masalah adalah bagaimana Strategi Pengembangan Wisata Di Desa Moat Kecamatan Moat Kabupaten Bolaang Mongondow Timur.

\section{Tujuan Penelitian}

Penelitian ini bertujuan menyusun Strategi untuk Pengembangan tempat wisata D'MOOAT.

\section{Manfaat Penelitian}

1. Penelitian ini bermanfaat untuk menambah ilmu pengetahuan dan wawasan bagi peneliti, dan dapat dijadikan referensi bagi penelitian lain dalam penelitian yang sama.

2. Bagi pemerintah Desa Moat Kabupaten Bolaang Mongondow Timur, diharapkan dapat menjadi bahan pertimbangan dalam menentukan kebujakan dalam peningkatan pariwisata yang ada di Kabupaten Bolaang Mongondow Timur Khususnya Desa Moat.

3. Sebagai bahan informasi bagi peneliti lainnya yang berhubungan dengan penelitian serupa. 


\section{METODE PENELITIAN}

\section{Waktu dan Tempat Penelitian}

Tempat pelaksanaan penelitian di tempat wisata D'MOOAT dilakukan selama 3 bulan, penelitan ini di laksanakan bulan Februari sampai April pada hari senin, rabu dan minggu setiap 1 bulan dan mewakili hari pertama kerja, hari ketiga dan hari libur. Lokasi penelitian dilaksanakan di tempat wisata D'MOOAT Desa Moat Kecamatan Moat Kabupaten Bolaag Mongondow Timur.

\section{Metode Pengambilan Data}

Data yang digunakan dalam penelitian ini yaitu data primer dan data sekunder. Data primer diperoleh dari wawancara langsung pada 51 orang dengan karyawan, pemilik D'MOOAT, Bapak Sangadi dan pengunjung yang datang ke tempat wisata D'MOOAT, data sekunder di peroleh dari studi literatur yang berkaitan dengan data yang dibutukan dalam penelitian.

Data yang diperoleh dalam bentuk tabel secara deskriptif. Pengumpulan seluruh data yang diperlukan dalam penelitian ini mengunakan beberapa cara yaitu:

1. Wawancara. Teknik ini digunakan untuk mengumpulkan data primer dengan wawancara langsung pada pemilik D'MOOAT berdasarkan daftar pertanyaan (kuisioner) yang telah disediakan.

2. Observasi. Observasi dilakukan melalui pengamatan langsung keberadaan tempat wisata D'MOOAT.

3. Dokumentasi. Pengambilan gambar data pendukung dari instansi atau lembaga yang mendukung penelitian.

\section{Faktor Internal}

\section{Konsep Pengukuran Variabel}

Faktor internal adalah faktor yang secara teknik dan logis harus dapat dikendalikan, faktor ini juga bisa merupakan kelemahan. faktor ini diantaranya:

Faktor Internal

a. Budaya meliputi:

Atraksi meliputi tarian khas dari Kabupaten

Bolaag Mongondow

b. Sumber Daya Alam meliputi:

1. Pemandangan meliputi: Panorama atau keindahan yang ada di tempat wisata D'MOOAT
2. Agroekologi ilmu yang cocok untuk tanaman stroberi dan bunga hias

c. Sumber daya Manusia Meliputi

Tenaga kerja meliputi karyawan untuk bidang pertanian dan cafe,

d. Fasilitas Meliputi:

1. Swafoto meliputi tempat foto yang ada di tempat wisata D'MOOAT

2. Tempat bermain meliputi ayunan, trampolin mini, seluncuran, kuda-kudaan dan wahana lainnya.

3. Cafe meliputi tempat makan, menu makanan, olahan makanan dan minuman dari hasil pertanian yang ada di dalam tempat wisata

4. MCK dan fasilitas kebersihan meliputi toilet, tempat pembuangan sampah di sekitar tempat wisata

5. Penginapan meliputi tempat istirahat di dekat tempat wisata

6. Promosi meliputi media online, media cetak, penyebaran kabar secara lisan

7. Tempat parkir meliputi kenyamanan tempat parkir, besar dan aman untuk kendaraan pengunjung

e. Pelayanan

1. Keramahan meliputi sikap dan tindakan pegawai maupun pemilik wisata D'MOOAT

2. Harga jual tiket masuk, parkir dan makanan meliputi harga murah, terjangkau, mahal.

\section{Faktor Eksternal}

Faktor eksternal adalah semua faktor dari luar yang relatif sulit dikendalikan. Faktor ini merupakan peluang, tapi sekaligus ancaman.

a. Infrastruktur meliputi:

1. Kondisi jalan menuju ke tempat wisata

2. lampu dan Rambu" lalu lintas

b. Transportasi meliputi:

1. Transportasi milik pribadi

2. Fasilitas transportasi umum yang tersedia

3. Transportasi mengunakan jasa travel

c. Persaingan meliputi jumlah tempat wisata yang ada di Desa Moat dan sekitarnya Dukungan pemerintah meliputi Kebijakan pemerintah, bantuan dan tanggapan masyarakat tentang tempat wiasata. 


\section{Metode Analisis Data}

\section{Analisis Deskriptif}

Penulis menggunakan metode penelitian analisis deskriptif yaitu dengan cara menggambarkan dan membahas keadaan serta kegiatan yang ada di dalam tempat wisata D'MOOAT di Desa Moat berdasarkan data dan informasi yang didapat dan di kumpulkan.

\section{Analisis SWOT}

a. Menurut Rangkuty (2017) cara perhitungan bobot dan rating dalam analisis SWOT: Menggunakan Kuesioner Yaitu

a) Kuesioner penilaian bobot menggunakan skala likert

Nilai $1=$ Tidak Penting

Nilai $2=$ Kurang Penting

Nilai $3=$ Cukup Penting

Niali $4=$ Penting

Niali $5=$ Sangat Penting

b) Kuesioner penilain Rating menggunakan skala likert

Untuk Faktor Kekuatan dan Peluang

Nilai $1=$ Kecil

Nilai $2=$ Cukup Besar

Nilai $3=$ Besar

Niali 4 = Sangat Besar

Untuk Faktor Kelemahan dan Acaman

Nilai $1=$ Sangat Besar

Nilai $2=$ Besar

Nilai $3=$ Cukup Besar

Niali $4=$ Kecil

Dalam penelitian ini penulis menggunakan kuesioner untuk menentukan atau memperoleh nilai bobot dan ranting.

\section{HASIL DAN PEMBAHASAN}

\section{Deskripsi Umum Tempat Penelitian}

Deskripsi Tempat wisata D'MOOAT di sebut Cafe Stroberi didirikan pada bulan April 2017 oleh Ibu Chyntia Loho yang berlokasi di Desa Moat Kecamatan Moat Kabupaten Bolaang Mongondow Timur. Awalnya, D'MOOAT merupakan lahan pertanian yang hanya ditanami tanaman hortikultura seperti kentang, wortel, daun bawang dan lain-lain. Dalam perkembanganya tidak memberikan panen yang memuaskan, lahan pertanian akhirnya beralih fungsi menjadi objek wisata D'MOOAT.
Tempat wisata alam ini di kenal dengan latar panorama yang indah, danau Moat dengan fasilitas yang ada kebun stroberi, tanaman bunga hias keunikan tempat wisata ini menarik wisatawan datang menikmati keindahan alam sambil menikmati sajian cafe stroberi, swafoto dan otbon atau tempat bermain, Pembanggunan tempat wisata terus di lakukan salah satunya adalah pembuatan tempat parkir sehingga menambah kenyamanan dan keamanan bagi para pengunjung atau wisatawan sehingga tidak menggangu sarana jalan yang ada, tempat parkir yang di sediakan dapat menampung kendaraan mobil, bus dan sepeda motor sehingga tidak menggangu transportasi umum yang ada.

Pelayanan yang di sediakan tempat wisata adalah dengan keramahan pada saat pengunjung datang ke tempat wisata D'MOOAT dan harga yang di tawarkan juga sangat terjangkau yaitu tiket masuk ke tempat wisata Rp.5.000/orang dan harga masuk untuk wahana bermain anak Rp.25.000/orang harga yang sangat terjangkau dan juga wasilitas bermain yang ada sangat bervariasi seperti seluncuran, trompolin,ayunan, kuda-kudaan,dan beberapa wahana lain yang unik dan aman bagi anak-anak untuk orang tua tersedia tempat untuk menunggu dan menjaga anak-anak yang sedang bermain tersedia juga ruang tunggu berada pada satu lokasi yang sama, Sejak bulan februari pengelolah wisata D'MOOAT mulai membanggun atau menambah fasilitas yang ada di tempat wisata penambahan dan perbaikan lahan atau media tanam bagi tanaman stroberi pembuatan green house untuk bunga-buanga hias dan fasilitas lainnya.

Kondisi wisata terus di kembangkan, berupa swafoto yang lebih menarik kebun stroberi dan bunga hias yang terus di kembangakan sehingga menambah daya Tarik tersenduri bagi pengungjung yang datang ke tempat wisata D,MOOAD.

Wisata D'MOOAT dibuka setiap hari dari pukul 07.00 sampai pukul 18.00 sedangkan kafe dibuka pada pukul 11.00 dan ditutup pada pukul 18.00 , tenaga kerja yang ada di wisata D'MOOAT adalah masyarakat di sekitaran Desa Maot dengan jumlah 16 orang, 5 orang untuk kebun stroberi dan tanaman hias dan 1 orang untuk tempat bermain anak dan 10 orang untuk kafe, tenaga 
kerja yang ada adalah masyarakat di sekitar tempat wisata D'MOOAT atau Desa Moat. Wisata D'MOOAT bukanlah satu-satunya tempat wisata yang ada di Desa Moat banyak tempat wisata yang sedang berkembang yaitu Villa Indah Moat, Cafe Love, Wisata Wisma, Kacamata Indah dan Cafe Molengku yang menawarkan pemandangan dan menjadi pesaing bagi D'MOOAT. Meskipun demikian banyaknya pesaing yang ada tidak membuat wisata D'MOOAT kekurangan pengunjung itu karena kekhasan berupa bunga hias, kebun stroberri, pemandangan, outbon, spot foto, cafe serta pelayanan. Kebersihan di tempat wisata ini terjaga dengan baik sehingga menjadi daya tarik tersendiri wisatawan, terdapat juga beberapa wahana lain yang masih dalam tahap penyelesaian seperti, budidaya stroberi yang terus di kembangkan sehingga juga menjadi daya tarik kuat, keunikan bagi tempat wisata D'MOOAT menyebabkan wisatawan terus mengunjungi dan menjadi tempat wisata yang populer bagi masyarakat Moat sekitar Sulawesi Utara dan luar Sulawesi Utara.

\section{Identifikasi faktor Internal Dan Faktor Eksternal}

\section{Faktor Internal}

\section{1) Budaya}

Atraksi tari-tarian khas kabupaten bolaang mongondow merupakan tarian uwela, tarian yang dilaksanakan oleh rakyat Bolaang Mongondow pementasan tarian hanya pada waktu acara-acara khus seperti mengerjakan kebun dan penjemputan tamu, destinasi tersebut sangat menarik bagi wisatawan yang ingin berkunjung ke Bolaang Mongondow.

\section{2) Sumber Daya Alam}

Pemandangan yang di tawarkan adalah Panorama atau keindahan yang ada di tempa wisata, danau Moat yang indah cakar alam, gunung ambang, spotfoto yang menarik dan unik yang ada di tempat wisata D'MOOAT menjadi daya tarik bagi wisatawan

Agroekologi di tempat wisata mendukung pengembangan tanaman stroberi dan bunga hias yang di budidayakan di tempat wisata D'MOOAT.

\section{3) Sumber daya Manusia}

Tenaga kerja yang bekerja di tempat wisata D'MOOAT adalah tenaga kerja untuk kebun dan café yang di serap dari sekitaran tempat wisata, tenaga kerja yang bekerja harus memilki ketrampilan yang di butuhkan oleh pemilik tempat wisata yaitu pengetahuan dan ahli dalam hal pertanian, cafe dan ahli bangunan. Pengetahuan tentang pertanian adalah tenaga kerja yang menguasai tentang lahan, budidaya hortikultura dan tanaman hias sehingga pengembangan tanaman hortikultura seperti buah stroberi dan bunga hias yang cocok pada iklim yang ada di Desa Moat dan harus di tangani oleh tenaga yang ahli dalam budidaya kedua tanaman tersebut.pengetahui tentang cafe yaitu dari juru masak yang menyediakan makanan dan minuman untuk pengunjung yang datang, pelayanan yang ramah bagi pengunjung wisata D'MOOAT serta pembangunan infastruktur yang ada di dalam tempat wisata seperti pembangunan tempat bermain anak, spot foto dan media tanam untuk stroberi dan bunga hias.

\section{4) Fasilitas}

1. Swafoto adalah spot-spot foto yang ada dan disediakan oleh pihak pengelolah seperti pemandangan alam danau Moat, keindahan bunga hias dan buah stroberi dan beberapa spot buatan yang menarik dan unik untuk menjadi spotfoto yang ada di tempat wisata D'MOOAT

2. Tempat bermain adalah wahana bermain bagi anak -anak yang ada di tempat wisata yaitu ayunan, trampolin mini, seluncuran, kudakudaan dan wahana lainnya.

3. Cafe adalah salah satu usaha yang ada di tempat wisata yang menyediakan tempat makan, menu makanan, olahan makanan dan minuman dari hasil pertanian yang ada di dalam tempat wisata

4. Mck dan fasilitas kebersihan tempat wisata harus memiliki toilet, tempat pembuangan sampah yang memadai serta bersih.

5. Penginapan tidak berada didalam tempat wisata melainkan di luar tempat wisata.

6. Promosi yang digunakan yaitu media sosial facebook, whatsapp, instragram yang mempromosikan tempat wisata D'MOOAT.

7. Tempat parkir sangat di butuhkan untuk kenyamanan wisatawan sehingga tidak menyebabkan kemacetan sehingga menggangu kenyamanan dalam perjalanan, tempat parkir harus besar dan aman untuk kendaraan pengunjung tempat wisata D'MOOAT. 


\section{5) Pelayanan}

Pelayanan adalah proses pemenuhan kebutuhan melalui aktivitas orang lain secara langsung. Sedangka adalah menolong menyediakan segala apa yang diperlukan orang lain seperti tamu atau pembeli. Pelayanan adalah aktivitas atau hasil yang dapat ditawarkan oleh sebuah lembaga kepada pihak lain yang biasanya tidak kasat mata, dan hasilnya tidak dapat dimiliki oleh pihak lain tersebut. berpendapat bahwa, pelayanan adalah aktivitas tambahan di luar tugas pokok (job description) yang diberikan kepada konsumen-pelanggan, nasabah, dan sebagainyaserta dirasakan baik sebagai penghargaan maupun penghormatan.

1. Keramahan adalah sikap dan tindakan seperti sapaan, senyum dan tutur kata serta tindakan pelayanan yang di tunjukan oleh pegawai maupun pemilik wisata D'MOOAT

2. Harga tiket baik tiket masuk, harga parkir dan harga makanan di tempat wisata D'MOOAT adalah harga yang terjangkau dan masih di golongkan murah, dengan harga Rp. 5.000 untuk biaya masuk ke tempat wisata dan Rp. 25.000 untuk biaya otbon untuk anak-anak, Rp.2000 biaya parkir danRp.15.000-30.000 untuk biaya makanan dan minuman yang ada di tempat wisata D'MOOAT.

\section{Faktor Eksternal \\ 1) Infrastruktur}

Infrastruktur adalah fasilitas yang ada serta mendukung kegiatan yang ada di setiap tempat, infrastruktur yang memadai sangat menunjang dan memperlancar segala kegiatan yang ada baik jalan maupun rambu dan lampu" jalan

a. Kondisi jalan menuju ke tempat wisata

Kondisi jalan yang memadai membuat para wisatawan menjadi nyaman sehingga perjalanan menjadi aman dan bebas resiko.

b. Lampu dan Rambu" lalu lintas

Lampu dan rambu sangat dibutuhkan karna hal"ini yang dapat membantu wisatawan dalam perjalanan serta menemukan tempat" fasilitas umum seperti pompa bensin penginapan bahkan tempat wisata yang akan dituju.

\section{2) Transportasi}

Kendaraan yang ada dan dapat di gunakan untuk sampai ke tempat wisata

a. Transportasi Pribadi

Transportasi milik pribadi adalah transportasi yang paling banyak di gunakan oleh wisatawan/pengunjung untuk datang ke tempat wisata D'MOOAT baik roda dua maupun roda empat.

b. Transportasi umum

Transportasi umum yang ada di sekitaran wisata alam D'MOOAT yaitu mikro, bentor dan taksi yang sering lewat, tetapi butuh waktu 30 menit- 1 jam untuk mendapatkan trasportasi

\section{3) Pesaing}

Tempat wisata yang ada di Moat ada villa indah Moat, Cafe love, Wisata Wisma, Kacamata Indah dan Cafe Malengku. Banyak tempat wisata yang ada di Desa Moat tetapi hanya D'MOOAT yang menawarkan wisata alam, otbon, cafe, swafoto, tanaman buah stroberi dan bunga hias yang menjadi daya tarik sendiri bagi wisatawan yang datang.

\section{4) Kebijakan Pemerintah dan Tanggapan Masyarakat}

Tempat wisata ini telah diakui dan diberi izin oleh pemerintah menjadi salah satu destinasi ungulan di bolaag mongondow timur, bantuan serta dukungan telah di berikan oleh pemerintah setempat,

Tanggapan masyarakat untuk tempat wisata ini sangat positif karna dapat juga membantu masyarakat seperti penyerapan tenaga kerja lokal, membuka pekerjaan baru seperti tukang ojek, bentor dan kios-kios hasil pertanian disekitar temapt wisata sehingga dapat memajukan ekonomi masyarakat karna banyak wisatawan yang datang ke D'MOOAT mampir atau berbelanja di sekitaran tempat wisata dimana masyarakat menjual hasil pertanian mereka dukungan juga dari masyarakat dengan selalu datang ke tempat wisata ini.

Bedasarkan uraian yang telah dikemukakan maka di identigikasi faktor internal dan faktor eksternal yang di sajikan dalam. 
Tabel 3. Identifikasi Faktor Internal dan Faktor Eksternal.

\begin{tabular}{|c|c|}
\hline Faktor Internal & Faktor Eksternal \\
\hline Kekuatan & Peluang \\
\hline $\begin{array}{l}\text { 1. Lokasi swafoto yang strategis } \\
\text { dengan pemandangan serta } \\
\text { spot menarik }\end{array}$ & $\begin{array}{l}\text { 1. Meningkatkan animo } \\
\text { masyarakat untuk datang } \\
\text { di tempat wisata }\end{array}$ \\
\hline $\begin{array}{l}\text { 2. Tempat untuk kebun stoberi } \\
\text { dan kebun bunga yang } \\
\text { menarik }\end{array}$ & $\begin{array}{l}\text { 2. Pemilik dapat terus } \\
\text { berinovasi dalam } \\
\text { mengembangkan tempat }\end{array}$ \\
\hline 3. Tersedia tenaga kerja yang & wisata \\
\hline $\begin{array}{l}\text { terampi dalam mengelola cafe } \\
\text { hasil pertanian }\end{array}$ & $\begin{array}{l}\text { 3. Meningkatkan pendapatan } \\
\text { tempat wisata sehingga }\end{array}$ \\
\hline $\begin{array}{l}\text { 4. Tersedia cafe yang } \\
\text { menawarkan olahan makanan } \\
\text { dan minuman hasil di tempat } \\
\text { wisata }\end{array}$ & $\begin{array}{l}\text { dapat menarik tenaga kerja } \\
\text { sekitar tempat wisata lebih } \\
\text { banyak }\end{array}$ \\
\hline $\begin{array}{l}\text { 5. Harga jual tiket, parkir, } \\
\text { makanan dan minuman yang } \\
\text { terjangkau }\end{array}$ & \\
\hline $\begin{array}{l}\text { 6. Tersedia fasilitas mck dan } \\
\text { tempat sampah }\end{array}$ & \\
\hline 7. Lokasi teampat wisata bersih & \\
\hline $\begin{array}{l}\text { 8. Peayanan dan keramahan } \\
\text { terhadap pengunjung }\end{array}$ & \\
\hline $\begin{array}{l}\text { 9. Adanya pengembangan } \\
\text { fasilitas tempat wisata yang } \\
\text { terus melakukan inovasi }\end{array}$ & \\
\hline $\begin{array}{l}\text { 10. Sebagai tempat untuk } \\
\text { memperkenalkan dan } \\
\text { promosi wisata alam yang } \\
\text { ada di BolaangMongondow } \\
\text { Timur }\end{array}$ & \\
\hline Kelemahan & Ancaman \\
\hline $\begin{array}{l}\text { 1. Belum adanya perkenalan } \\
\text { budaya daerah di tempat } \\
\text { wisata }\end{array}$ & $\begin{array}{l}\text { 1. Kondisi jalan yang } \\
\text { berbelok dan kurangnya } \\
\text { rambu dan lampu jalan }\end{array}$ \\
\hline penginapan & 2. Bermunculan berbagai \\
\hline 3. Tempat parkir yang belum & objek wisata lain disekitar \\
\hline $\begin{array}{l}\text { 4. Promosi yang digunakan } \\
\text { masih menggunakan media } \\
\text { social facebook }\end{array}$ & dengan pihak travel \\
\hline
\end{tabular}

\section{Strategi Pengembangan Wisata Di Desa Moat Kecamatan Moat Kabupaten Bolaag Mogondow Timur}

\section{Hasil Evaluasi Lingkungan Internal (IFAS) dan Hasil Evaluasi Lingkungan Eksternal (EFAS)}

Setelah dilakukan indentifikasi terhadap faktor internal dan eksternal yang berpengaruh terhadap perkembangan wisata di Desa Moat khususnya D'MOOAT maka selanjutnya dilakukan evaluasi terhadap faktor -faktor tersebut baik dari kekuatan dan kelemahan yang ada dengan menggunakan Analisis Internal Faktor Strategi (IFAS), dan faktor- faktor peluang dan ancaman yang ada dengan menggunakan Analisis Eksternal Faktor Strategi (EFAS) Berdasarkan evaluasi yang dilakukan diperoleh hasil bobot,ranting dan nilai skor yang dapat dilihat pada Tabel 4.

\begin{tabular}{llll} 
Tabel 4. Strategi Internal Temapat Wisata D'MOOAD & & & \\
\hline No Faktor Faktor Strategi Internal & Bobot & Rating & Skor \\
\hline Kekuatan & & & \\
1. Lokasi foto yang strategis dan pemandangan serta spot & 0,1002 & 3,80 & 0,3807 \\
menarik & 0,1001 & 3,82 & 0,3823 \\
2. Tempat untuk kebun stroberi dan kebun bunga yang & & & \\
menarik dan dibudidayakan sendiri & 0,1001 & 3,84 & 0,3843 \\
3. Tersedia tenaga kerja yang trampil dalam mengelolah & 0,0992 & 3,84 & 0,3809 \\
hasil pertanian & & & \\
4. Tersedia cafe yang menawarkan olahan makanan dan & 0,1001 & 3,90 & 0,3903 \\
minuman hasil pertanian di tempat wisata & 0,1002 & 3,84 & 0,3847 \\
5. Harga jual tiket, parkir, makanan dan minuman yang & 0,1002 & 3,84 & 0,3847 \\
terjangkau & 0,1002 & 3,96 & 0,3967 \\
6. Tersedia fasilitas mck dan tempat sampah & 0,0995 & 3,84 & 0,3820 \\
7. Lokasi tempat wisata bersih & & & \\
8. Keramahan dan pelayanan terhadap pengunjung & 0,1002 & 3,98 & 0,3988 \\
9. Adanya pengembangan fasilitas tempat wisata yang & 1 & & 3,8660 \\
terus melakukan inovasi & & & \\
10. Sebagai tempat untuk memperkenalakan dan promosi & & & \\
bagi wisata alam yang ada di Bolaang Mongondow & & & \\
Timur & & & \\
Total & & & \\
\hline$\quad$ Kelemahan & & & \\
\hline 1. Belum adanya perkenalan budaya daerah di tempat & 0,2399 & 3,58 & 0,8588 \\
wisata & 0,2585 & 2,48 & 0,6410 \\
2. Tidak tersedianya tempat penginapan & 0,2601 & 1,70 & 0,4421 \\
3. Tempat parkir yang belum memadai & 0,2415 & 1,46 & 0,3525 \\
4. Promosi yang dilakukan masih mengunakan media & 1 & & 2,2946 \\
sosial facebook & & & \\
Total & & & \\
\hline
\end{tabular}

Total bobot $\mathrm{x}$ ranting pada tabel diatas faktor kekuatan bernilai 3,8660 dan faktor kelemahan bernilai 2,2946 yang digunakan sebagai acuan titik kondisi internal pada tempat wisata D'MOOAT hasil ini digunakan untuk melihat posisi pengembangan usaha wisata saat ini.

\begin{tabular}{|c|c|c|c|c|}
\hline No. & $\begin{array}{c}\text { Faktor-Faktor Strategi } \\
\text { Eksternal }\end{array}$ & Bobot & Ranting & Skor \\
\hline & Peluang & & & \\
\hline 1. & $\begin{array}{l}\text { Meningkatnya animo } \\
\text { masyarakat untuk datang } \\
\text { di tempat wisata }\end{array}$ & 0,3476 & 0,3476 & 1,3208 \\
\hline 2. & $\begin{array}{l}\text { Pemilik dapat terus } \\
\text { berinovasi dalam } \\
\text { mengembangkan tempat } \\
\text { wisata }\end{array}$ & 0,3209 & 0,3209 & 1,2130 \\
\hline \multirow[t]{2}{*}{3.} & $\begin{array}{l}\text { Meningkatkan } \\
\text { pendapatan tempat } \\
\text { wisata sehingga dapat } \\
\text { menarik tenaga kerja } \\
\text { sekitar tempat wisata } \\
\text { lebih banyak }\end{array}$ & 0,3315 & 0,3315 & 1,2928 \\
\hline & Total & 1 & & 3,8267 \\
\hline 1. & $\begin{array}{l}\text { Ancaman } \\
\text { kondis jalan yang } \\
\text { berbelok dan kurangnya } \\
\text { rambu dan lampu jalan } \\
\text { menuju tempat wisata }\end{array}$ & 0,3476 & 1,46 & 0,7825 \\
\hline 2. & $\begin{array}{l}\text { Bermunculan berbagai } \\
\text { alternatif objek wisata } \\
\text { lain di sekiar }\end{array}$ & 0,3209 & 2,12 & 0,9836 \\
\hline \multirow[t]{2}{*}{3.} & $\begin{array}{l}\text { Belum ada kerja sama } \\
\text { dengan pihak terkait } \\
\text { seperti jasa pariwisata } \\
\text { dan trevel }\end{array}$ & 0,3315 & 1.88 & 0,5662 \\
\hline & Total & 1 & & 1,8158 \\
\hline
\end{tabular}


Berdasarkan hasil matriks IFAS dapat dilihat bahwa faktor strategis internal kekuatan memiliki nilai skor sebesar 3,8660 sedangkan faktor strategi inter4nal kelemahan memiliki nilai skor sebesar 2,2946. Hal ini menunjukan bahwa faktor kekuatan lebih tinggi di bandingkan dengan faktor kelemahan. Selanjutnya, hasil matriks EFAS pada faktor strategi eksternal peluang memiliki nilai skor sebesar 3,8267 sedangkan faktor strategi eksternal ancaman memiliki nilai skor sebesar 1,8158 . Hal ini berarti tempat wisata D'MOOAT di Desa Moat memiliki peluang yang lebih besar untuk mengantisipasi ancaman dalam menentukan strategi pengembangan.

\section{Diagram analisis SWOT}

Berdasarkan hasil perhitungan skor faktor strategi internal dan eksternal maka dapat diketahui bahwa nilai x sebagai sumbu horizontal yaitu faktor kekuatan 3,8660 dikurangi fakthor kelemahan 2,2946 dengan selisi 1,5714 dan nilai sumbu y sebagai sumbuh vertikal yaitu faktor peluang 3,8267 dikurangi faktor ancaman 1,8158 dengan selisih 2,0109. Dengan demikian nilai sumbuh $\mathrm{x}$ dalam diagram SWOT adalah 1,5714 dan nilai sumbu y dalam diagram analisi SWOT adalah 2,0109.

Gambar 4. Hasil yang di dapat dari matriks IFAS dan EFAS dalam diagram SWOT berarti usaha pengembangan wisata D'MOOAT di Desa Moat memiliki kekuatan yang lebih besar untuk menghadapi kelemahannya dan peluang yang lebih besar untuk mengantisipasi ancaman dalam menentukan strategi pengembangannya.

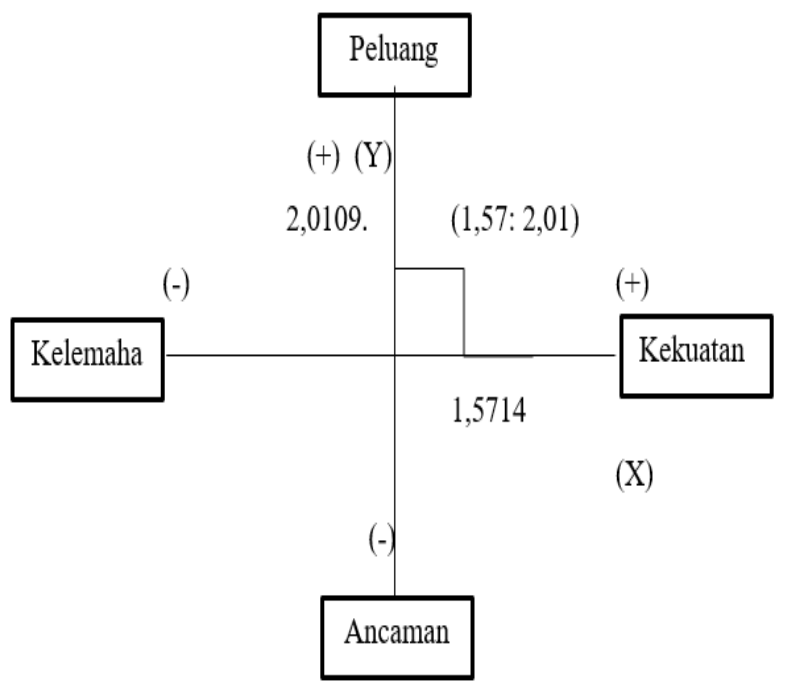

Pada diagram analisis SWOT diatas menunjukan bahwa usaha pengembangan wisata D'MOOAT memiliki kekuatan dan peluang sehingga dapat memanfaatkan peluang yang ada. Strategi yang dapat diterapkan dalam kondisi ini adalah mendukung kebijakan pertumbuhan yang agresif (Growth oriented strategy). Freddy Rangkuti (2017:20).

\section{Matriks SWOT}

Berdasarkan Tabel 6. Diatas diperoleh beberapa alternatif strategi yang bisa diaplikasikan dalam pengembangan wisata di Desa Moat dalam upaya memaksimalkan kekuatan dan memanfaatkan peluang serta meminimalkan kelemahan dan mengatasi ancaman yang ada sebagai berikut:

I. Strategi SO

1. Mempertahankan dan meningkatkan fasilitas dan berinovasi sehingga menciptakan spot foto, outbon dan atraksi yang lebih menarik sehingga meningkatkan daya tarik atao animo dari wisatawan dan masyarakat untuk datang ke tempat wisata

2. Mempertahankan pelayanan dan kebersihan dalam tempat wisata dan meningkatkan pendapatan tempat wisata sehinga dapat menarik tenaga kerja dari sekitar Desa dan tempat wisata

\section{Strategi WO}

Menghadirkan atraksi budaya lokal meningkatkan sarana dan prasarana dalam tempat wisata seperti tempat parkir dan memanfaat promosi yang ada untuk meningkatkan animo masyarakat untuk datang di tempat wisata

III. Strategi ST

Meningkatkan kualitas dan mempertahankan inovasi-inovasi dan kreatifitas yang unik yang ada di tempat wisata sehingga menjadi daya tarik tersendiri bagi wisatawan dan dapat bekerja sama dengan pihak- pihak terkait

\section{Strategi WT}

1. Menghadirkan atraksi budaya untuk menjadi daya tarik wisatawan karna mengangkat budaya daerah dan menjadi kekuatan dan promosi bagi tempat wisata D'MOOAT

2. Menghadirkan atraksi budaya untuk menjadi daya tarik wisatawan karna mengangkat budaya daerah dan menjadi kekuatan dan promosi bagi tempat wisata D'MOOAT. 


\begin{tabular}{|c|c|c|}
\hline & Strength $(\mathbf{S})$ & Weakness (W) \\
\hline EFAS & $\begin{array}{l}\text { 1. Lokasi foto yang strategis dan pemandangan serta } \\
\text { spot menarik } \\
\text { 2. Tempat untuk kebun stroberi dan kebun bunga yang } \\
\text { menarik dan dibudidayakan sendiri } \\
\text { 3. Tersedia tenaga kerja yang trampil dalam } \\
\text { mengelolah hasil pertanian } \\
\text { 1. Tersedia cafe yang menawarkan olahan makanan } \\
\text { dan minuman hasil pertanian di tempat wisata } \\
\text { 2. Harga jual tiket, parkir, makanan dan minuman yang } \\
\text { terjangkau } \\
\text { 3. Tersedia fasilitas mck dan tempat sampah } \\
\text { 4. Lokasi tempat wisata bersih } \\
\text { 5. Keramahan dan pelayanan terhadap pengunjung } \\
\text { 6. Adanya pengembangan fasilitas tempat wisata yang } \\
\text { terus melakukan inovasi } \\
\text { 7. sebagai tempat untuk memperkenalakan dan } \\
\text { promosi bagi wisata alam yang ada di Bolaang } \\
\text { Mongondow Timur }\end{array}$ & $\begin{array}{l}\text { 1. Belum adanya } \\
\text { perkenalan budaya } \\
\text { daerah di tempat } \\
\text { wisata } \\
\text { 2. Tidak Tersedianya } \\
\text { tempat penginapan } \\
\text { 3. Tempat parkir yang } \\
\text { belum memadai } \\
\text { 4. Promosi yang } \\
\text { dilakukan masih } \\
\text { mengunakan media } \\
\text { sosial facebook }\end{array}$ \\
\hline $\begin{array}{l}\text { Opportunity }(\mathbf{O}) \\
\text { 1. Meningkatnya animo } \\
\text { masyarakat untuk datang } \\
\text { di tempat wisata } \\
\text { 2. Pemilik dapat terus } \\
\text { berinovasi dalam } \\
\text { mengembangkan tempat } \\
\text { wisata } \\
\text { 3. Meningkatkan } \\
\text { pendapatan tempat } \\
\text { wisata sehingga dapat } \\
\text { menarik tenaga kerja } \\
\text { sekitar tempat wisata } \\
\text { lebih banyak }\end{array}$ & $\begin{array}{l}\text { Strategi SO } \\
\text { 1. Mempertahankan dan meningkatkan fasilitas serta } \\
\text { inovasi sehingga sehingga meningkatkan daya tarik } \\
\text { atau animo dari wisatawan dan masyarakat untuk } \\
\text { datang ke tempat wisata } \\
\text { 2. Mempertahankan pelayanan dan kebersihan dalam } \\
\text { tempat wisata dan meningkatkan pendapatan tempat } \\
\text { wisata sehinga dapat menarik tenaga kerja dari sekitar } \\
\text { Desa dan tempat wisata }\end{array}$ & \begin{tabular}{l}
\multicolumn{1}{c}{ Strategi WO } \\
Menghadirkan atraksi \\
budaya lokal \\
meningkatkan sarana \\
dan prasarana dalam \\
tempat wisata seperti \\
tempat parkir dan \\
memanfaat promosi \\
yang ada untuk \\
meningkatkan animo \\
masyarakat untuk \\
datang di tempat wisata
\end{tabular} \\
\hline $\begin{array}{l}\text { Treath }(\mathbf{T}) \\
\text { 1. kondis jalan yang } \\
\text { berbelok dan kurangnya } \\
\text { rambu dan lampu jalan } \\
\text { menuju tempat wisata } \\
\text { 2. Bermunculan berbagai } \\
\text { alternatif objek wisata } \\
\text { lain di sekiar } \\
\text { 3. Belum ada kerja sama } \\
\text { dengan pihak terkait } \\
\text { seperti jasa pariwisata } \\
\text { dan trevel }\end{array}$ & $\begin{array}{l}\text { Strategi ST } \\
\text { 1. Meningkatkan inovasi-inovasi dan kreatifitas yang } \\
\text { unik yang ada di tempat wisata dan mempertahankan } \\
\text { keramahan dalam pelayanan sehingga menjadi daya } \\
\text { tarik tersendiri bagi wisatawan } \\
\text { 2. Bekerjasama dengan travel untuk meningkatkan } \\
\text { jumlah wisatawanit }\end{array}$ & $\begin{array}{l}\text { Strategi WT } \\
\text { 1. Menghadirkan atraksi } \\
\text { budaya una } \\
\text { menjadi daya tarik } \\
\text { wisatawan karna } \\
\text { mengangkat budaya } \\
\text { daerah dan menjadi } \\
\text { kekuatan dan } \\
\text { promosi bagi tempat } \\
\text { wisata D'MOOAT } \\
\text { 2. Miningkatkan } \\
\text { promosi bagi } \\
\text { wisatawan sehingaa } \\
\text { dapat bekerja sama } \\
\text { dengan pihak terkait } \\
\text { untuk meningkatkan } \\
\text { jumlah wisatawan } \\
\text { yang datang ke } \\
\text { tempat wisata }\end{array}$ \\
\hline
\end{tabular}




\section{KESIMPULAN DAN SARAN}

\section{Kesimpulan}

Strategi yang tepat untuk pengembangan wisata di Desa Moat Kecamatan Moat Kabupaten Bolaang mongondow Timur adalah dengan menerapkan strategi agresif, yaitu strategi SO mempertahankan dan meningkatkan fasilitas dan berinovasi sehingga menciptakan spot foto, outbon dan atraksi yang lebih menarik sehingga meningkatkan daya tarik atau animo dari wisatawan dan masyarakat untuk datang ke tempat wisata

Selain menggunakan strategi SO sebagai pilihan strategi utama, juga harus tetap memperhatikan atau meninjau ketiga alternatif strategi yaitu strategi Wo, strategi ST, dan strategi WT.

\section{Saran}

a. Bagi pemilik Usaha D'MOOAT yaitu tetap mempertahankan dan meningkatkan fasilitas dan berinovasi menciptakan spotspot foto yang menarik, mempertahankan pelayanan kebersihan dan keunikan di dalam tempat wisata tetap mengembangan tempat wisata, terus membuat trobosan baru sehingga tempat wisata dapat di kenal bukan hanya wisata dalam negeri tapi luar negeri.

b. Pemerintah Kabupaten Bolaang Mongondow Timur untuk dapat membantu pemilik usaha untuk mengembangkan wisata seperti bantuan dana, sarana prasarana sehingga bukan hanya pemilik yang di untungkan tetapi masyarakat dan daerah juga mendapat keuntungan untuk kemajuan pariwisata yang ada di Bolaang Mongondow Timur.

\section{DAFTAR PUSTAKA}

Abdurahman. 2015. Manajemen Strategi Pemasaran.: $\quad \mathrm{Cv}$. Pustaka.Setia Bandung.

Dirgantoro, C. 2001. Manajemen Strategi. Gramedia widia Sarana Indonesia. Jakarta.

Rangkuty, F. 2017. Analisis SWOT Teknik Membedah Kasus Bisnis. PT, Grammedia Pustaka Utama. Jakarta.

Siagian, S. P. 2017. Manajemen Strategi. PT. Bumi Aksara, Jakarta.

Suwantoro, G. 2004. Dasar-dasar Pariwisata. Yogyakarta: Penerbit Andi.

Widyastuti, F. R. 2013. Strategi Promosi Wisata pada Dinas Kebudayaan, Pariwisata, Pemuda dan Olahraga Kabupaten Temanggung. Jurnal. 